\title{
Rituximab for Treatment of Focal Segmental Glomerulosclerosis in a Child: A Case Report
}

\author{
Zhengkun Xia*, Yu Zhou*, Yuanfu Gao*, Zhongmin Fan*, Chunlin Gao, Song Mao, Xu He, Zhuo Shi, Tao Sun, Pei Zhang, Hongjun Peng and \\ Min Xu
}

Department of Pediatrics, Nanjing Jinling Hospital, China

\begin{abstract}
Objective: To study the efficacy of rituximab in children with focal sclerosing glomerulonephritis (FSGS).

Case Report: Before treatment, blood biochemistry, hepatic and renal function, differential white cell counts, immunoglobulins and the complement system were assessed. Promethazine $(0.5-1 \mathrm{mg} / \mathrm{kg})$ and methylprednisolone $(0.1-0.3 \mathrm{mg} / \mathrm{kg})$ were administered intravenously $30 \mathrm{~min}$ and 5-10 $\mathrm{min}$ before the rituximab infusion. Rituximab $(0.27 \mathrm{~g})$ was diluted in $300 \mathrm{ml}$ glucose solution and initially administered at $50 \mathrm{ml} / \mathrm{hr}$ the rate increased to $50 \mathrm{ml} / \mathrm{hr}$ every $30 \mathrm{~min}$ after no side effects occurred in the first hour. A second dose was given one month later. During treatment, prednisone (30 mg) was taken on alternate days. Benazepril $(3.3 \mathrm{mg})$ was administered every day with one chongcao capsule. Homemade ershenkang was given three times a day. Outcome: Eyelid and limb edema declined two weeks after the first application of rituximab and resolved after the second treatment. Urinary protein levels decreases, serum albumin increased, and white cell counts, hepatic function and renal function remained constant. After 3 months of followup, urine protein decreased significantly, and serum albumin $(35.2 \mathrm{~g} / \mathrm{L})$ and cholesterol $(5.4 \mathrm{mmol} / \mathrm{L})$ normalized. Parameters of immune activation also reduced, and the patient remained well.
\end{abstract}

Conclusion: In this case, rituximab was a safe and efficacious treatment for FSGS.

Keywords: Rituximab; Pediatrics; Sclerosing; Glomerulonephritis; Therapy

\section{Introduction}

For refractory nephropathy in children who are resistant to the classical treatment, such as steroid or immunosuppressive agents, B Cell Depletion Therapy (BCDT) may be a useful option. BCDT is specific for the removal of $\mathrm{B}$ cells by apoptosis; the most commonly use medicine currently is rituximab. Rituximab is an anti-CD20 humanrat mosaic monoclonal antibody that has been constructed by gene recombination technology $[1,2]$. It has been used in recent years in the treatment of B-cell lymphoma, rheumatoid arthritis, systemic lupus erythematosus, idiopathic thrombocytopenic purpura, refractory nephrotic syndrome and other autoimmune diseases. The following paper reports the clinical application of rituximab in a single pediatric case with focal sclerosing glomerulonephritis (FSGS).

\section{Case Report}

A 4-yr-old male patient (17 kgs) presented to his local hospital with edematous eyelids and lower limbs without an apparent cause in October 2008.His urine protein level was $3+$, with a serum albumin of $20.6 \mathrm{~g} / \mathrm{L}$ and cholesterol of $13.7 \mathrm{mmol} / \mathrm{L}$; the diagnosis of Nephritic Syndrome (NS) was made. The patient was given prednisone $(35 \mathrm{mg})$ every day. One month later, his urinary protein was still positive, and the patient was given methylprednisolone pulse therapy ( $0.5 \mathrm{~g}$ for 3 days each week for 3 weeks). The dose of prednisone was gradually reduced. Cyclophosphamide pulse therapy (Iv) was then administered $(0.5 \mathrm{~g}$ once a month for 6 months). His parents gave an unknown traditional Chinese medicine for one month. Despite these treatments, the urinary protein remained $3+$, the amount of eyelid edema did not reduce, and the 2 -hr urine protein was $2.75 \mathrm{~g} / \mathrm{L}$. Mycophenolate mofetil was applied once a month four times; after each treatment, a month later the renal biopsy revealed FSGS. Tacrolimus (1 mg) was also administered twice a day. Three months later, the clinical symptoms did not improve, and urinary protein levels were still $4+$.

The patient was referred to Jinling Hospital for further treatment. After admission, physical examination showed edema of the lower limbs and eyelids, full consciousness, no reddened throat, swollen tonsils, or abnormalities on heart and lung auscultation. There was no pleural rub. The abdomen was soft without tenderness, and there were no abnormalities of the nervous system. Laboratory examinations revealed proteinuria at $4+$, red blood cells 1200/ul, ascorbic acid +, NAG enzyme $25.1 \mathrm{u} / \mathrm{g} \bullet \mathrm{cr}$, urinary retinol binding protein $0.31 \mathrm{mg} / \mathrm{L}$, urinary C3 $2.71 \mathrm{ng} / \mathrm{L}$, and urinary a2-M $2.95 \mathrm{ng} / \mathrm{L}$. Full blood count analysis revealed WBC $7.9 \times 10^{9} / \mathrm{L}$, (neutophills 0.61 ,lymphocytes 0.39 ) hemoglobin $102 \mathrm{~g} / \mathrm{L}$, platelets $268 \times 10^{9} / \mathrm{L}$. Serum albumin was 24.1 $\mathrm{g} / \mathrm{L}$, cholesterol $9.5 \mathrm{mmol} / \mathrm{L}$, triglyceride $2.75 \mathrm{mmol} / \mathrm{L}$, glucose 3.8 $\mathrm{mmol} / \mathrm{L}$, blood urea nitrogen $(\mathrm{BUN}) 4.4 \mathrm{mmol} / \mathrm{L}$, creatinine $(\mathrm{Cr}) 58$ $\mathrm{mmol} / \mathrm{L}, \mathrm{ALT} 7 \mathrm{u} / \mathrm{L}$, aspartate aminotransferase $18 \mathrm{u} / \mathrm{L} ; \mathrm{IgG} 0.690 \mathrm{~g} / \mathrm{L}$, IgA0.313 g/L, IgM0.520 g/L, IgE21.5 Iu/ml, C3 0.899 g/L, C4 0.350 $\mathrm{g} / \mathrm{L}, \mathrm{CRP}<3.20, \mathrm{RF}<20$, anti-O $<25 \mathrm{Iu} / \mathrm{ml}$. Clotting analysis showed the following: activated thromboplastin time 27.4 seconds, fibrinogen $382 \mathrm{mg} / \mathrm{dl}$, prothrombin time 10.6 seconds, and thrombin time 17.3

*Corresponding authors: Zhengkun Xia, Department of Pediatrics, Nanjing Jinling Hospital, 305 East Road, ZhongShan, Nanjing 210002, P. R. China, Tel: +86 25 80861386; E-mail: njxzk@126.com

Yu Zhou, Department of Pediatrics, Nanjing Jinling Hospital, 305 East Road ZhongShan, Nanjing 210002,P.R.China. Tel: (+86 25) 80861386; E-mail: zyu87@163.com

Yuanfu Gao, Department of Pediatrics, Nanjing Jinling Hospital, 305 East Road ZhongShan, Nanjing 210002,P.R.China. Tel: (+86 25) 80861386; E-mail: gaoyf9199@163.com

Zhongmin Fan, Department of Pediatrics, Nanjing Jinling Hospital, 305 East Road ZhongShan, Nanjing 210002,P.R.China. Tel: (+86 25) 80861386; E-mail: fanzhongmin@126.com

Received February 17, 2014; Accepted March 24, 2014; Published March 27 2014

Citation: Xia Z, Zhou Y, Gao Y, Fan Z, Gao C, et al. (2014) Rituximab for Treatment of Focal Segmental Glomerulosclerosis in a Child: A Case Report. J Nephrol Therapeutic S1: 009 doi:10.4172/2161-0959.S1-009

Copyright: @ 2014 Xia Z, et al. This is an open-access article distributed under the terms of the Creative Commons Attribution License, which permits unrestricted use, distribution, and reproduction in any medium, provided the original author and source are credited. 
seconds. CD3 +75.0 \%, CD4 + CD3 +36.0 \%, CD $8+\mathrm{CD} 3+38.0 \%$, Th: Ts0.95; CD19 + 127a/ul, CD19 + Gate $6.34 \%$, CD20 + 103a/ul, CD20 + Gate $5.15 \%$.B ultrasound showed no abnormal renal sonogram.

A repeated renal pathology showed the following: 19 glomeruli, where 11 showed glomerular sclerosis with hyalinization, glomerular capsule fibrosis, reduced glomerular volume, capillary lumen occlusion, part of the ball wall adhesion, tubular atrophy, dilation, and renal interstitial fibrosis. Immunofluorescence showed IgG (-), IgA (-), IgM (+++), C3 (-), and C1q (-) (Figures 1-7).

After the mechanism and dosage of rituximab was explained to the guardians of the patient, informed consent was obtained. Phenergan $(0.5-1 \mathrm{mg} / \mathrm{kg})$ was injected intravenously half an hour before treatment, and dexamethasone was injected intravenously 5 to 10 minutes before treatment. Rituximab $(0.27 \mathrm{~g})$ was diluted in $300 \mathrm{ml} 5 \%$ glucose solution. The initial fluid infusion rate was $50 \mathrm{ml} / \mathrm{hr}$, and the dose was increased one hour later in the absence of side effects to $100 \mathrm{ml} / \mathrm{hr}$. One month later, the second intravenous infusion was taken. Prednisone $(30 \mathrm{mg}$ ) was given every other day on a gradually reducing dose, and benazepril $(3.3 \mathrm{mg})$ was taken once a day, and cordyceps capsules $(0.45$ g)were taken three times a day with our self-produced ershenkang (a kind of traditional Chinese medicine), which was beneficial for the renal diseases.

\section{Results}

After the first infusion of rituximab, the edema of the eyelid

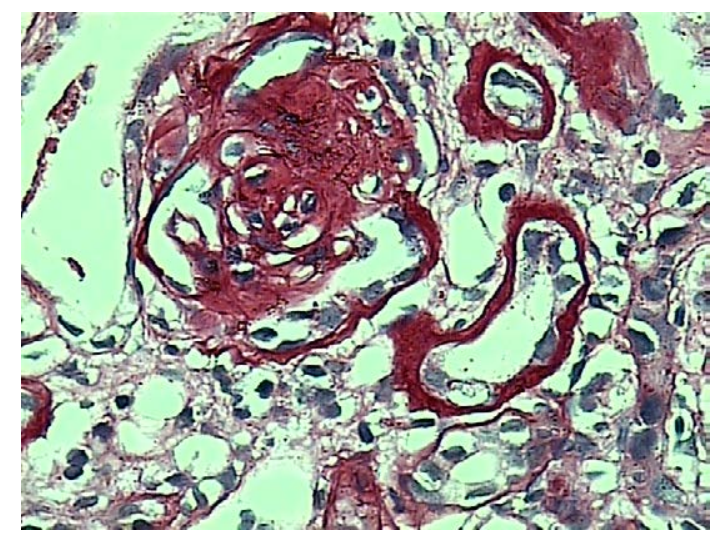

Figure 1: PAS staining was positive staining of glomerular sclerosis.

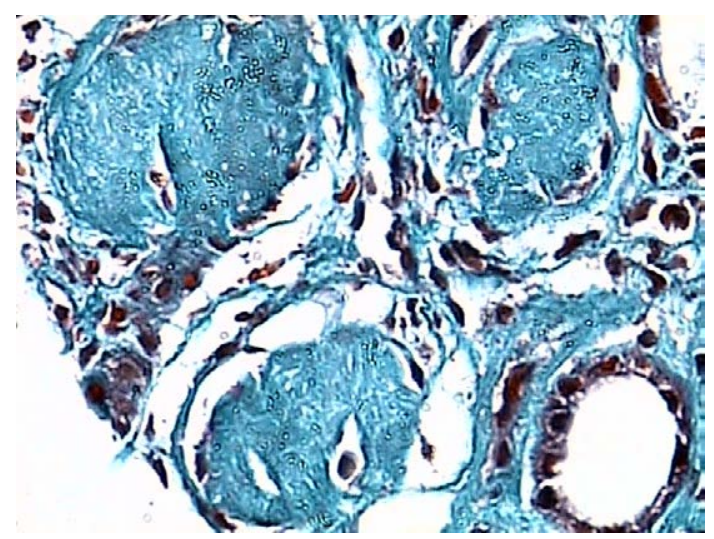

Figure 2: Massom staining showed glomerular sclerosis concentration of interstitial fibrosis.

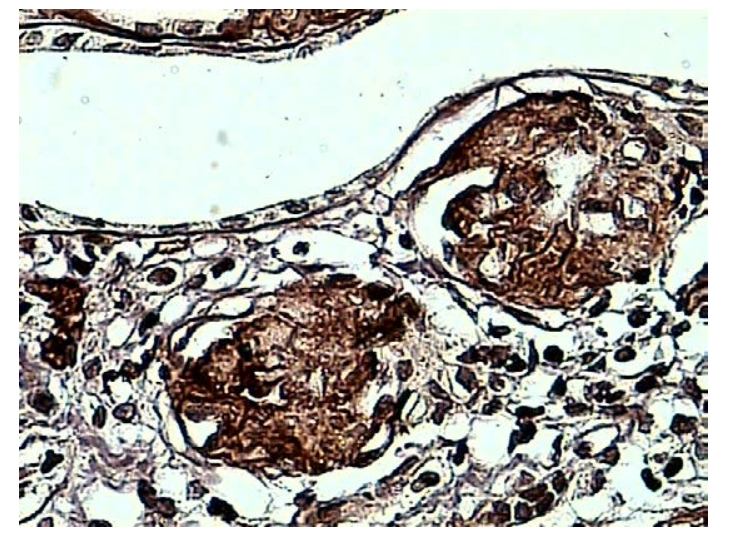

Figure 3: PAM within the reticular fiber proliferation of glomerular sclerosis.

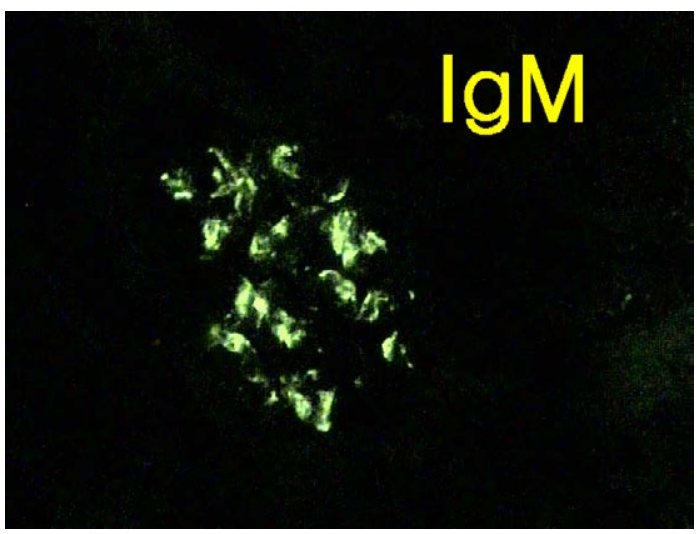

Figure 4: The IgM staining showed massive deposition in the mesangial area.

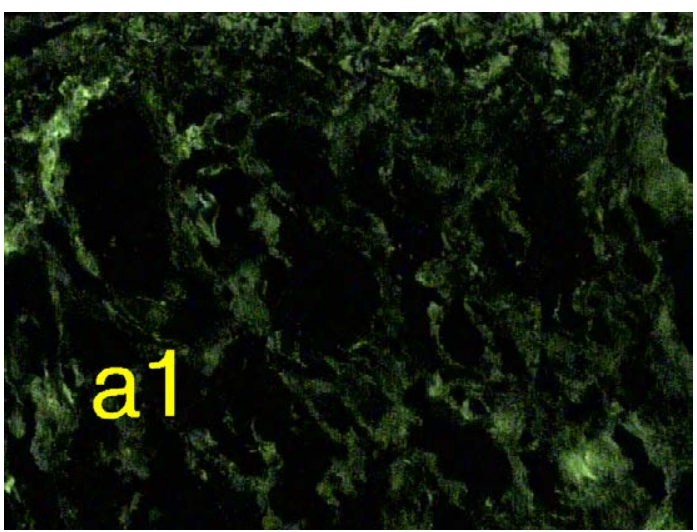

Figure 5: Fluorescent staining of type IV collagen a1 chain deposition in the renal interstitium.

and lower extremities decreased, and disappeared after the second intravenous infusion. There was no hydrothorax. One month after the first intravenous infusion of rituximab, serum albumin increased, cholesterol and triglycerides had no apparent change, while liver and kidney functions and blood parameters were both normal; three months after the second infusion, the blood leukocytes were $5.2 \times 10^{9} / \mathrm{L}$, (N -0.46, L-0.52) Hb-121-g/L, Plt-341 $\times 10^{9} / \mathrm{L}$; serum albumin was $35.2-\mathrm{g} / \mathrm{L}$, cholesterol was $5.4-\mathrm{mmol} / \mathrm{L}$, triglyceride was $1.94 \mathrm{mmol} / \mathrm{L}$, 


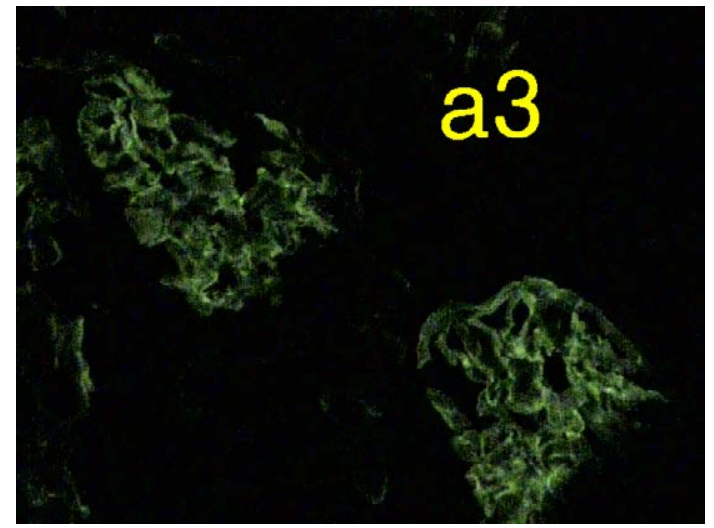

Figure 6: a3 chain staining showed a linear glomerular basement membrane deposition.

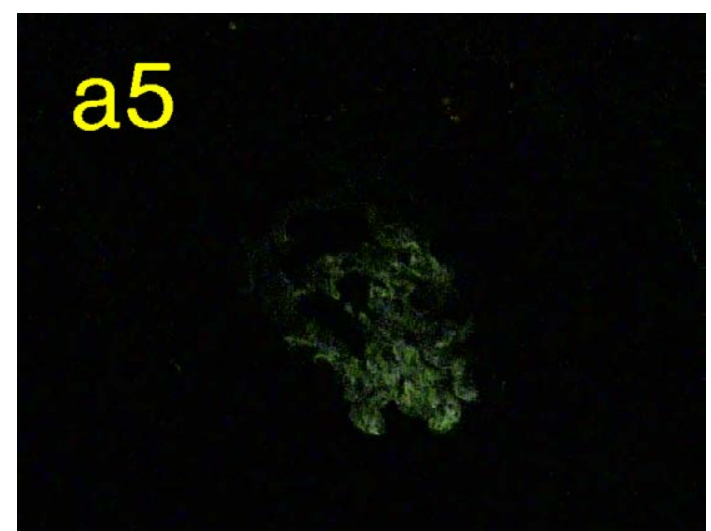

Figure 7: a5 chain staining showed a linear glomerular basement membrane deposition.

\begin{tabular}{|c|c|c|c|}
\hline & $\begin{array}{c}\text { Before the } \\
\text { treatment }\end{array}$ & $\begin{array}{c}\text { after the first } \\
\text { infusion }\end{array}$ & $\begin{array}{c}\text { after the second } \\
\text { infusion }\end{array}$ \\
\hline Urinary protein & $4+$ & $2+$ & $1+$ \\
\hline 24-hr urinary protein (g/L) & 1.71 & 0.68 & 0.32 \\
\hline urinary NAG enzyme(u/g•cr) & 25.1 & 17.2 & 13.4 \\
\hline urinary retinol binding protein & 0.31 & 0.29 & 0.32 \\
\hline $\begin{array}{c}\text { (mg/L) } \\
\text { urinary C3 (ng/L) }\end{array}$ & 2.71 & 2.75 & 2.8 \\
\hline urinary $\mathbf{\alpha 2 - M}$ (ng/L) & 2.95 & 2.78 & 2.96 \\
\hline
\end{tabular}

Table 1: The change before and after the intervention of rituximab.

glucose was $3.9 \mathrm{mmol} / \mathrm{L}$; BUN was 5.8-mmol/L, creatinine $(\mathrm{Cr})$ was 64 $\mathrm{mmol} / \mathrm{L}$; ALT was $4 \mathrm{u} / \mathrm{L}$, aspartate aminotransferase $14 \mathrm{u} / \mathrm{L}$; IgG 3.25 g/L, IgA $0.29 \mathrm{~g} / \mathrm{L}, \operatorname{IgM} 0.742 \mathrm{~g} / \mathrm{L}, \operatorname{IgE} 20 \mathrm{Iu} / \mathrm{ml}, \mathrm{C} 31.08 \mathrm{~g} / \mathrm{L}, \mathrm{C} 40.35$ $\mathrm{g} / \mathrm{L}$, anti-O $<25 \mathrm{Iu} / \mathrm{ml} ; \mathrm{CD} 3+61.0 \%, \mathrm{CD} 4+\mathrm{CD} 3+25.0 \%, \mathrm{CD} 8+\mathrm{CD} 3$ $+36.0 \%$, Th: Ts0.69; CD19 +6 a/ul, CD19 + Gate $0.3 \%$, CD20 +6 a/ul, $\mathrm{CD} 20+$ Gate $0.3 \%$. There were no side effects during or after treatment with rituximab (Table 1)

\section{Discussion}

Rituximab is a chimeric IgG1 mouse/human monoclonal antibody, which is specifically designed against the CD20 antigen in the cell membrane. This antigen is located in the pre- and mature $\mathrm{B}$ lymphocytes, but does not exist in the hematopoietic stem cells, pro-B cells, normal plasma cells or other normal tissues.
Rituximab has been given in recurrent or chemotherapy-resistant $B$ cell types in non-Hodgkin's lymphoma, due to its specific inhibition of $\mathrm{B}$ cells, and indirect action against $\mathrm{T}$ cells. It has gradually been applied to other clinical immune complex diseases, such as systemic lupus erythematosus and refractory thrombocytopenic purpura, among others. In recent years, clinicians have applied rituximab to refractory renal diseases, to refractory renal diseases $[3,4]$, although this has not been attempted in China.

In this paper, rituximab was given to a child with FSGS and, two weeks after the first intravenous infusion, edema of the eyelids and lower extremities declined. A gradual improvement in clinical and laboratory parameters was observed, and the edema resolved completely within a month of the second treatment infusion. No adverse effects of treatment were observed. The numbers of $\mathrm{T}$ helper cells and B lymphocytes both decreased, while the levels of other blood cells and overall liver and kidney function were not affected. The results showed that rituximab plays a role in both the humoral and cellular immune function through targeted therapy against B cells [5].

Several crucial points should be adhered to during the application of rituximab: i) rituximab should be diluted in sterile conditions in sodium chloride or $5 \%$ glucose solution to a concentration of $1 \mathrm{mg} /$ $\mathrm{ml}$, and the infusion bags of mixed solution should be inverted gently to prevent foaming; ii) the initial intravenous speed for the first hour of the infusion was $50 \mathrm{mg} / \mathrm{hr}$, which then increased by $50 \mathrm{ml}$ every 30 minutes. The maximum speed remained less than $300 \mathrm{mg} / \mathrm{hr}$; iii) rituximab should be used with caution in patients with a neutrophil count of less than $5 \times 10^{9} / \mathrm{L}$ and/or the platelet count was less than $75 \times 10^{9} / \mathrm{L}$ patients. During treatment, the neutrophil and platelet counts should be monitored regularly; iv) if any allergic reaction occurs, the patient should be treated appropriately with standard agents, such as epinephrine, antihistamines and corticosteroids [6].

This study reports the safe and effective use of rituximab in the treatment of refractory focal sclerosing glomerulonephritis in a child. This was apparently mediated through the significant decrease in circulating B cells and it provides a new approach for patients with difficult B cell-mediated renal disease.

\section{References}

1. Warrier R, Chauhan A (2012) Management of immune thrombocytopenic purpura: an update. Ochsner J 12: 221-227.

2. Iseki M, Omori-Miyake M, Xu W, Sun X, Takaki S, et al. (2012) Thymic stromal lymphopoietin (TSLP)-induced polyclonal B-cell activation and autoimmunity are mediated by CD4+ T cells and IL-4. Int Immunol 24: 183-195.

3. Wiesik-Szewczyk E, Olesinska M (2012) B-cell targeted therapy in systemic lupus erythematosus: potential of rituximab. Biologics 6: 347-354.

4. Lan L, Han F, Chen JH (2012) Efficacy and safety of rituximab therapy for systemic lupus erythematosus: a systematic review and meta-analysis. J Zhejiang Univ Sci B 13: 731-744.

5. Prytula A, lijima K, Kamei K, Geary D, Gottlich E, et al. (2010) Rituximab in refractory nephrotic syndrome. Pediatr Nephrol 25: 461-468.

6. Ejaz AA, Asmar A, Alsabbagh MM, Ahsan N (2012) Rituximab in immunologic glomerular diseases. MAbs 4. 